Uluslararası Yönetim Íktisat ve İsletme Dergisi, ICAFR 16 Özel Sayısı Int. Journal of Management Economics and Business, ICAFR 16 Special Issue

\title{
ULUSLARARASI FINANSAL RAPORLAMA STANDARTLARININ KAPSAMI: SEÇILMIŞ 7 SEKTÖR BAZINDA İNCELEME
}

\author{
Arş. Gör. Dr. Şuayyip Doğuş DEMİRCI \\ Sakarya Üniversitesi İşletme Fakültesi İşletme Bölümü \\ sdemirci@sakarya.edu.tr \\ Arş. Gör. Bilge ÖNAL \\ Kocaeli Üniversitesi SBE, Sakarya Üniversitesi SBE YL. Öğrencisi \\ bilge.onal@kocaeli.edu.tr
}

\section{ÖZET}

1973 yılından hazırlanmaya başlanan, 2005 senesinde Avrupa Birliği (AB) tarafindan üye ve aday ülkelerde uygulama zorunluluğu getirilen Uluslararası Finansal Raporlama Standartlarl (UFRS) tüm sektörlerde muhasebe uygulamalarında değişikliklere neden olmuştur. Yapılan bu çalışmada UFRS'lerin kapsamında sektörel bazda benzerlikler ve farklılıklar incelenmiştir. Standartların çoğunun tüm sektörleri

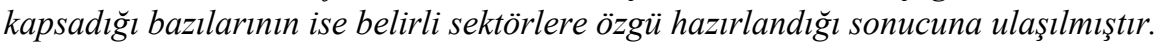

Anahtar Kelimeler: Finansal Muhasebe, Uluslararası Muhasebe Standartları.

\section{SCOPE OF INTERNATIONAL FINANCIAL REPORTING STANDARTS: REVIEW OF 7 SELECTED SECTORS}

\begin{abstract}
The IFRS, which were started to prepare in 1973, have led to changes in accounting practices in all sectors. All EU-members and member candidates were required to implement the IFRS after 2005. This study examines the similarities and differences of the IFRS' scope based on sectors. The fund of this study is that most of the standards contain every sector, and some of the standards are just made for specific sectors.
\end{abstract}

Keyword: Financial Accounting, International Accounting Standarts.

\section{Giriş}

Ülkelerin kendilerine özgü hukuk sistemlerine, hukuksal ve vergisel düzenlemelere, sosyal, ekonomik, dini ve kültürel çevrelere sahip olması, muhasebe sistemlerinde de farklılıklara neden olmuştur. Bunun sonucunda farklı ülkelerde farklı 


\section{Uluslararası Yönetim İktisat ve İsletme Dergisi, ICAFR 16 Özel Sayısı Int. Journal of Management Economics and Business, ICAFR 16 Special Issue}

muhasebe sistemleri ortaya çıkmıştır (Wiecek \& Young, 2010, s. 1). Çok uluslu şirketler zaman içerisinde hızlı bir şekilde artış göstermiş ve farklı ülkelerde pazar paylarını arttırmışlardır. Uluslararası ticaret yapan bu şirketler ülkelerin muhasebe sistemlerinde bulunan farklılıklar neticesinde muhasebeleştirmede zorluklarla karşılaşmaya başlamışlardır (Epstein \& Mirza, 1999, s. 8). Bu durum finansal tabloları şeffaflıktan uzak bir hale getirmiş ve karşılaştırılabilirliğini zorlaştırmıştır. Bu yüzden uluslararası ticarette tek düze, şeffaf ve dünya üzerinde finansal piyasalarda etkin bir muhasebe sistemi oluşturulması konusu gündeme gelmiştir.

Küreselleşmenin neticesinde ticari hayatta uluslararası şirketler için uluslararası bir muhasebe dili ihtiyacı ortaya çıkmıştır (Türker \& Yarbaşı, 2005, s. 52) . Bu konu 1972 yılında Avustralya'da düzenlenen 10. Dünya Muhasebeciler Kongresinde gündeme gelmiş ve Uluslararası Muhasebe Standartları Komitesinin kurulması konusunda anlaşmaya varılmıştır (Alfredson vd, 2009, s. 3; Ernst\&Young, 2010, s. 4). Uluslararası Muhasebe Standartları Komitesi (IASC) 1973 y1lında 9 ülkenin katılımıyla (Avustralya, Kanada, Fransa, Almanya, Japonya, Meksika, Hollanda, Birleşik Krallık ve İrlanda ve ABD) kurulmuştur (Kikuya, 2001, s. 350). Kurulan bu komitenin amacı tek set yüksek kalitede, anlaşılabilir, yaptırım gücüne sahip ve küresel düzeyde geçerli olacak muhasebe standartları oluşturmaktır (IFRS, 2015). Bu amaçla komite Uluslararası Muhasebe Standartları (UMS) oluşturmaya ve yayınlamaya başlamıştır.

Uluslararası Muhasebe Standartları Komitesinin faaliyetleri uzun bir süre kabul görmemiştir. $\mathrm{Bu}$ durum çeşitli nedenlerden kaynaklanmıştır. $\mathrm{Bu}$ nedenler kısaca (Alfredson vd, 2009, s. 3) ;

- Komitede bulunanların ulusal standart oluşturma faaliyetleri içinde yer almaması. Komite üyelerinin ulusal standart oluşturan kurum ve kuruluşlarla zayıf ilişkiler içinde olması,

- 25 ylllk deneme neticesinde Ulusal Standartlar ile Uluslararası Muhasebe Standarları'nın (UMS) yakınsanamaması,

- Komite üyelerinin asıl işinin standart oluşturmak olmaması, komitede yarı zamanlı çalışmaları,

- Yeterli kaynak ve teknik destekten mahrum kalmaları olarak siralanabilir.

Yukarıda belirtilen nedenlerden ötürü komitenin hazırlamış olduğu standartlar uygulamaya konulamamıştır. 1995 senesinde Uluslararası Menkul Kıymetler Komitesi (IOSCO: International Organization of Securities Commission) ile yapılan anlaşma neticesinde standartların IOSCO'ya üye ülkelerde uygulanması gündeme gelmiştir (Akman, 2009, s. 7). IOSCO'nun desteğinden sonra Avrupa Komisyonu (EC: European Commision) üye ve aday ülkelerinde uygulatmak üzere komitenin hazırlamış olduğu UMS'lerin uygulanması konusunda bir açıklama yapmıştır. 2000 yılının Haziran ayında AB tüm aday ve üye ülkelerinde UMS'leri uygulayacağını açıklamıştır (Epstein \& K.Jermakowicz, 2010, s. 6; Ernst\&Young, 2010, s. 51). Ancak komitenin yapısının profesyonel olmaması ve AB'nin standartları yetersiz görmesinden ötürü 2000 yılının Temmuz ayında faaliyetlerinin daha verimli gerçekleştirilebilmesi için komitenin küçültülerek tam zamanlı çalışan profesyoneller ile birlikte Uluslararası Muhasebe Standartları Kuruluna dönüştürülmesine karar verilmiştir (Alfredson vd. , 2009, s. 3).

1963 yılından günümüze uzanan Türkiye'nin AB'ye üyelik sürecinde Avrupa Birliğine uyum sağlamak amacıyla Türkiye'de birçok gelişmeye imza atılmıştır. (Uysal, 


\author{
Uluslararası Yönetim İktisat ve İsletme Dergisi, ICAFR 16 Özel Sayısı \\ Int. Journal of Management Economics and Business, ICAFR 16 Special Issue
}

2001) Fakat Türkiye'de Uluslararası Muhasebe Standartlarına uyumlu çalışmalar yapmak için, Avrupa Birliğinin 2000 yılında yaptığı açıklamayı beklemeksizin, 1994 yılında TMUDESK (Türkiye Muhasebe ve Denetim Standartları Kurulu) kurulmuştur. (Bostanc1, 2002). TMUDESK'in oluşturduğu Standartların herhangi bir yasal yaptırımı olmadığından dolayı, 1999 yılında devlet desteği ile UMSK (Türkiye Muhasebe Standartları Kurulu) kurulmuştur (Üstünel, 2003; Kocamaz, 2012). Bu kurul ile İASCF arasında Türkiye'de uygulanacak olan Standartların, 2005 yılından itibaren kullanılması planlanan UMS'lerle uyumlu olması amacıyla bir telif ve lisans anlaşması yapılarak, UMS'lerin Türkçeye çevrilerek devralınmasına karar verilmiştir (Bekçi \& Özdemir, 2006). Türkiye'de UMSK 2002 yılının ortalarında faaliyete geçerek 2009 yılına kadar Resmi Gazete'de 10'u UMS 8'i TFRS olmak üzere 18 Standart ve 10'u UMSY ve 17'si TMFRSY olmak üzere 28 yorum yayınlamıştır (Yalkın, Demir, \& Demir, 2008; Başpınar, 2004; Kocamaz, 2012). Günümüze bakacak olursak 2015 y1lı itibariyle toplamda 14 TFRS, 28 adet de UMS bulunmaktadır. (Kamu Gözetim Kurumu, b.t.)

Standartların büyük bir kısmı tüm sektörleri kapsayan nitelikteyken, bazı standartlar belirli sektörlere özel olarak hazırlanmıştır. Genel nitelikli hazırlanan standartların bir kısmı da çeşitli sektörleri kapsamamaktadır. Yapılan bu çalışmada belirlenen 7 sektörü (Banka, Sigorta, Yatırım Fonu, Gayrimenkul, İnşaat, Maden ve Petrol) hangi standartların kapsayıp hangi standartların kapsamadığı incelenmiştir. Öncelikli olarak bu sektörlerle ilgili literatür çalışması yapılmış olup, ardından uygulama kısmında sektörel bazda standartların kapsamı incelenmiştir.

\title{
2. Literatür Taraması
}

Yulong (2005) sigorta şirketleri için oluşturulan UFRS 4 standartını Çin muhasebe sistemi açısından incelemiştir. Gutterman (2013) TFRS 4 Sigorta sözleşmeleri standartı ve diğer standartların sigorta sektörüne etkisini incelemiştir. Şenyiğit (2012) çalışmasında hangi TFRS'lerin Türk sigorta sektöründe uygulandığını incelemiştir. Podoaba (2015) kaza ve hayat sigortası primlerinde UFRS 4 ve Solvency II düzenlemeleri sonrasında ortaya çıkan farklılıkları incelemiştir. Şişmanoğlu \& Arıkboğa (2011) çalışmalarında TFRS'lerin sigorta şirketlerindeki etkisini incelemişlerdir. Yücel, Öncü, \& Kartal (2015) çalışmalarında Türkiye'de 2007-2014 yılları arasında yapılmış olan akademik çalışmaları incelemişlerdir. Çalışmalarında Sigorta sözleşmeleri standartı olan TFRS 4 ile ilgili herhangi bir yayın tespit etmemişlerdir. Ayrıca TFRS 10 ile ilgili 2 yayın, TFRS 13 ile ilgili 1 yayın yapıldığı belirlenmiştir. İnşaat şirketleriyle alakalı ise 16 tane yayın yapıldığı belirlenmiştir. Ara dönem finansal tabloların sunuluşu ile alakalı olarak hazırlanan UMS 34 standartı ile ilgili ise hiçbir yayın bulunamamıştır.

Agostino vd. (2011) çalışmalarında Avrupa banka sektörünü UFRS’lerin uygulamaya konulmasından önce ve sonra olarak incelemişlerdir. Uygulamaya konulan UFRS'ler çerçevesinde şirketlerin hisse fiyatları muhasebe bilgisindeki değişiklikler neticesinde artış göstermiştir. Bischof (2009) UFRS 7 standartının 2007 yılında yürürlüğe girmesiyle $28 \mathrm{AB}$ ülkesinde 171 bankanın dipnotları üzerine etkisini incelediği çalışmasında, standartın uygulamaya girmesiyle finansal durum tablosunun ve risk raporlarının kalitesinin arttığ 1 tespit edilmiştir. Firoz vd. (2011) UFRS'lerin 2011 yılında uygulamaya konulmasının Hindistan bankacılık sektörüne etkilerini incelemişlerdir. Yapılan çalışmada bankacılık sektörüne en çok etki eden standartın UFRS 9 olduğunu bulmuşlardır. Gebhardt ve Novotny-Farkas (2011) UFRS'lerin uyumlaştırılmasının 


\section{Uluslararası Yönetim İktisat ve İsletme Dergisi, ICAFR 16 Özel Sayısı Int. Journal of Management Economics and Business, ICAFR 16 Special Issue}

Avrupa bankalarında muhasebe raporlamalarındaki yapmış olduğu değişikliği incelemişler ve UMS 39 standartının bankaların gelirlerini düşürdüğü sonucuna ulaşmışlardır. Gebhardt vd. (2004) finansal enstürmanlar Standartdının (UMS 39) bankalar üzerindeki etkisini incelemişlerdir. Heykal vd. (2013) yapmış oldukları çalışmada UFRS'lerin banka sektörüne etkisini halka açık 11 banka üzerinden değer düşüklüğü karşılıkları ile bankaların kredi tutarlarında farklılıkları incelemişlerdir. Manganaris vd. (2015) çalışmalarında bankacılık sektörünün finansal tablolarının UFRS'lerin uygulamaya başlanmasıyla geçirdiği değişimi incelemiş ve raporlama kalitesinin arttığını tespit etmişlerdir. Özdemir (2015) çalışmasında TFRS 8 standartına göre bankalarda yapılacak raporlamayı incelemiştir. Quagli \& Ricciardi (2010) 2008 Ekim UMS 39 standartının 71 banka üzerindeki etkisini incelemişler ve sermaye yönetimini ilgilendiren ciddi bir farklılık gözlemlememişlerdir. Thappa (2012) çalışmasında UFRS'lerin uyumlaştırılmasının Hindistan bankacılık sistemine olan etkisini incelemiştir.

Spies \& Wilhelm (2005) çalışmalarında UFRS ve US GAAP arasında gayrimenkul değerleme metotları arasında bulunan farklılıkları incelemişlerdir. Christensen \& Nikolaev (2009) UFRS'ler ile uygulamaya konulan gerçeğe uygun değer yaklaşımının tarihi maliyet yaklaşımı ile karşılaştırıldığında gayrimenkul sektöründe daha çok tercih edildiğini belirlemişlerdir. Muller vd. (2011) gerçeğe uygun değerin Avrupa gayrimenkul sektöründe etkilerini inceledikleri çalışmalarında, UMS 40 standartının bilgi asimetrisini UMS 'leri zorunlu uygulamaya koyan şirketlerde isteğe bağlı uygulayan şirketlere göre daha olumlu yönde etkilediğini belirlemişlerdir. A.Quagli ve F.Avallone (2010) standartların bilgi asimetrisi, sözleşmelerin üzerine yaptığı etkiyi ve yönetimsel değişiklikleri inceleyen çalışmalarında UMS 40 standartının etkisini incelemişlerdir. Çalışmada standartların gerçeğe uygun değer ile raporlama yapılması durumunda maliyetlerin daha düşük olduğu sonucuna ulaşmışlardır. Nellessen \& Zuelch (2011) çalışmalarında gayrimenkul sektörü için UFRS'ler ile birlikte gelen gerçeğe uygun değer üzerinden ölçümü incelemişlerdir.

Neveling (2006) yapmış olduğu haberde UFRS'lerin petrol şirketi BP'nin kârını büyük ölçüde azalttığı ve BP ye ait olan türev ürünlerinden ötürü finansal tablolarında büyük değişikliklere neden olduğu bildirmiştir. Brooks (2008) yapmış olduğu haberde UFRS 6 standartı ile petrol ve maden sektöründe ortaya çıkacak muhasebe farklılıklarını ve başarısız sonuçlanan araştırma maliyetlerinin giderleştirilmesi mi yoksa aktifleştirilmesi mi gerektiğini incelemiştir. Noel, Ayayi, \& Blum (2010) muhasebe standartı oluşum sürecini etik açıdan inceledikleri çalışmalarında komitenin ekonomik ve

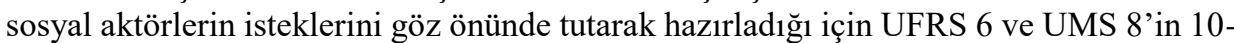
12. Maddeleri arasından hareket ederek standartların etik sorunlara sahip olduğu bulgusuna ulaşmışlardır. Cortese (2013) Maden ve petrol şirketlerinin kullanacağı UFRS 6 standartının oluşum sürecini kurula yollanan yorum mektupları açısından incelemiştir. Gürarda \& Ateş (2015) maden ișletmelerinin finansal tablolarının dipnotlarının UFRS'ler ile uyumunu araştırdıkları çalışmalarında şirketlerin çoğunun yetersiz bilgi verdikleri sonucuna ulaşmışlardır. Özkan \& Aksoylu (2012) çalışmalarında madenlerin araştırması esnasında ortaya çıkan giderlerin TFRS 6 standartına göre incelemişlerdir. Çalışmaya göre hasılat net gerçeğe uygun değer ile raporlanırken, yapılan harcamalar doğrudan gider yazılacaktır. L.Cortese, Irvine, \& Koidonis (2010) UFRS 6 standartının oluşum sürecinde bir uluslararası muhasebe şirketinin, bir küresel madencilik şirketinin ve bir sanayi 
Uluslararası Yönetim İktisat ve İsletme Dergisi, ICAFR 16 Özel Sayısı Int. Journal of Management Economics and Business, ICAFR 16 Special Issue

grubundan oluşan gizli koalisyonun standart oluşum sürecini nasıl etkilediğini incelemişlerdir.

DeFond, $\mathrm{Hu}, \& \mathrm{Li}$ (2011) uluslararası yatırım şirketlerinin UFRS'leri kullanıma başlaması durumunda finansal tablolarında ortaya çıkacak farklılıkları inceledikleri çalışmalarında zorunlu UFRS kullanımının karşılaştırılabilirliği arttırdığı sonucuna ulaşmışlardır. Yu \& Wahid (2014) yatırım şirketlerinin ve yatırım yapılan ülkelerde finansal tabloların UFRS ile uyumlaştırılmasının etkilerini inceledikleri çalışmalarında UFRS'lerin uyumlaştırılmasının yatırım şirketleri için herhangi bir etkisinin olmadığına yalnızca standartlara olan aşinalığı arttırdığı sonucuna ulaşmışlardır. Oswald (2008) yazısında UFRS ve US GAAP'ın yakınsama çalışmalarının yatırım şirketlerinin finansal tablolarında ortaya çıkaracağı farklılıkları ele almıştır. Yazısında yatırım fonlarının sınıflandırılması, broker komisyon ücretleri, menkul kıymetlerin değerlendirilmesi ve konsolidasyon konularında farklılıklar olduğunu belirtmiştir.

Yereli, Kayalı, \& Demirlioğlu (2011) çalışmalarında UMS 11 ile ulusal uygulamalarda bulunan sözleşme yöntemleri açısından farklılıkları ortaya koymuşlardır. Karaca \& Misket (2014) çalışmalarında UMS 11 standartının İnşaat Şirketlerinin finansal tablolarına etkisini incelemiş ortaya çıkan farkların muhasebeleştirilmesi hususunda örnekler vermişlerdir. Badem \& Tosun (2013) yıllara yaygın inşaat ve onarım işlemlerinin VUK ve UMS 11 açısından farklılıklarını inceledikleri çalışmalarında UMS 11 'in finansal tablolara etkisini ve UMS 12 standartını incelemişlerdir. Çelik vd. (2015) çalışmalarında TMS 11 - İnşaat sözleşmeleri standardında öngörülen tamamlanma yüzdesine göre muhasebe uygulamalarına değinmişlerdir.

\section{Uygulama}

Çalışma, Ernst\&Young şirketi tarafindan 2014 ve 2015 yılları sonunda "Good Group International Limited" adı ile yayınlanan, seçilmiş sektörler bazında standartların uygulanması ve raporlanmasıyla ilgili örneklem üzerinden yapılmıştır (Ernst\&Young, 2014) (Ernst\&Young, 2015). Ernst\&Young tarafından seçilen sektörler kendisine has muhasebe uygulamaları olan sektörlerden oluşmaktadır.

\section{Çalışmanın Amacı ve Kapsamı:}

Çalışma Banka, Sigorta, İnşaat, Gayrimenkul, Yatırım Fonu Ortaklı̆̆ı, Maden ve Petrol Sektörlerini kapsamaktadır.

Çalışmada mevcut standartların (16 UFRS, 28 UMS ve Standart Yorumları) hangilerinin yukarıda belirtilen sektörlerde uygulanması gerektiği incelenmiştir. Ayrıca sektörler bazında standartların hangilerinin sıklıkla kullanıldığı hangilerinin ise sektöre özgü olduğu irdelenmiştir.

\section{Çalışmanın Kısıtları:}

Çalışmada tüm sektörler ele alınmamıştır. Çalışmanın amacı ve kapsamı kısmında belirtilen sektörler üzerinden çalışma gerçekleştirilmiştir.

Çalışmada 16 tane olan UFRS'lerin 3 tanesi henüz uygulamaya konulmadığı için (UFRS 14 01.01.2016, UFRS 15 01.01.2018, UFRS 16 01.01.2019) çalışmaya konu edilmemiştir. 
Uluslararası Yönetim Íktisat ve İsletme Dergisi, ICAFR 16 Özel Sayısı Int. Journal of Management Economics and Business, ICAFR 16 Special Issue

Yukarıda belirtilen 7 sektör öncelikli olarak UMS'ler açısından, daha sonra UFRS'ler ve yorumlar bazında incelenmiştir. Grafik 1'de UMS'lerin 7 sektörde kapsamı gösterilmiştir. Sektörel bazda bakıldığ 1 zaman UMS'lerin en çok inşaat sektöründe (22 UMS), en az ise yatırım fonu sektörünü (12 UMS) kapsadığı görülmektedir. Gayrimenkul sektöründe 21 standart, sigorta ve petrol şirketlerinde 20 adet standartın sektörleri kapsadığı görülmektedir.

Tablo 1'de UMS'lerin sektörlere göre kullanım sıklığı gösterilmiştir. Tabloya göre 12 UMS'nin (UMS 1, UMS 7, UMS 8, UMS 10, UMS 12, UMS 18, UMS 21, UMS 24, UMS 32, UMS 33, UMS 37, UMS 39) içeriği tüm sektörleri kapsamaktadır. Sektörler bazında spesifik özelliğinden ötürü en az kullanılan standart UMS 20 Devlet Teşviklerinin Muhasebeleştirilmesi Ve Devlet Yardımlarının Açıklaması standartıdır. Bu standart yalnızca inşaat sektörünü ilgilendirmektedir. UMS 20'den sonra kapsamı en az olan iki standart UMS 11 İnşaat Sözleşmeleri standartı (İnşaat ve Gayrimenkul Sektörü) ve UMS 40 Yatırım Amaçlı Gayrimenkuller (Sigorta ve Gayrimenkul Sektörü) standartıdır. UMS 11 ve UMS 40 standartlarının beraber uygulanması gereken tek sektör Gayrimenkul sektörüdür.

\section{Grafik 1:UMS’lerin Sektörlere Göre Kullanımı}

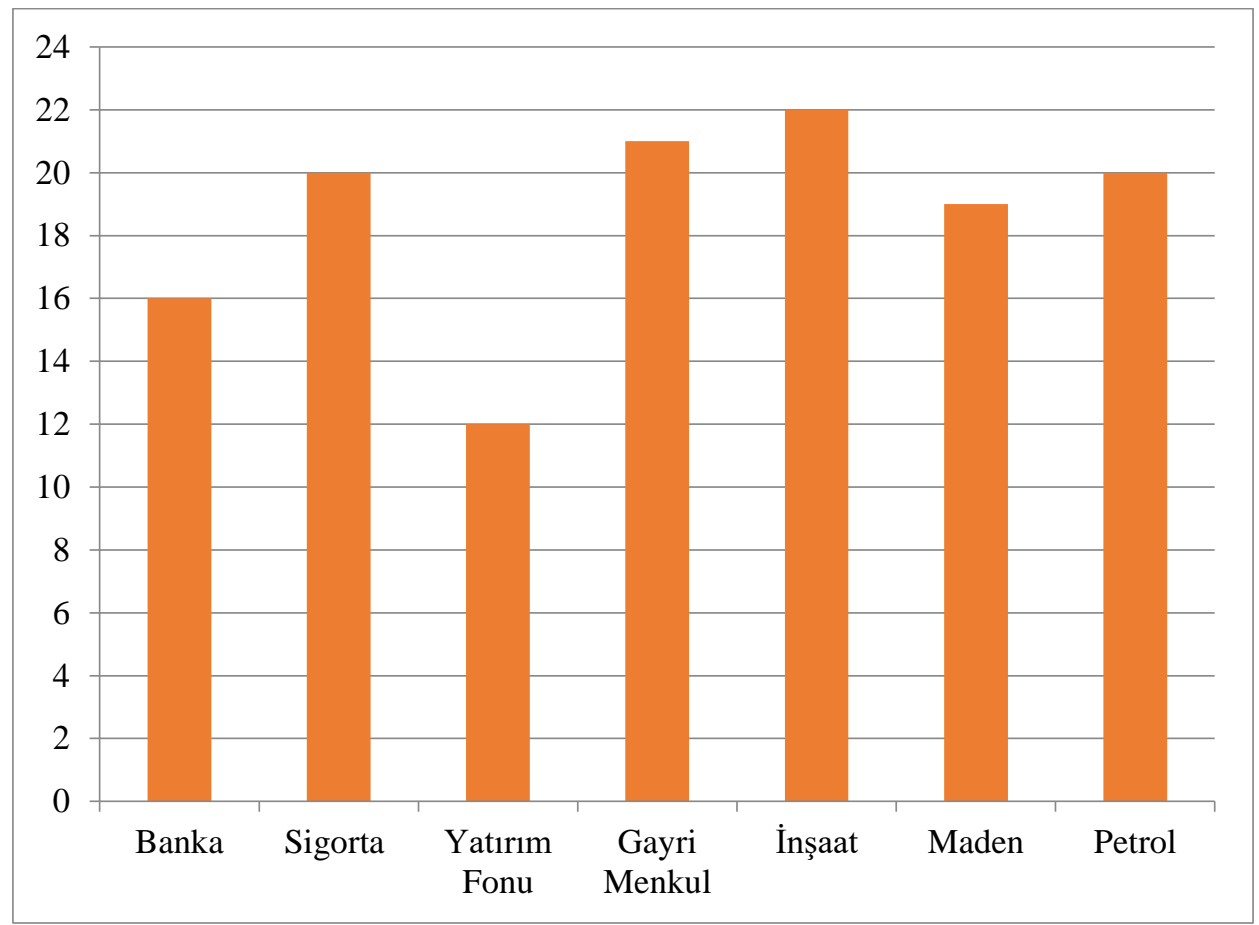

Kaynak: E\&Y Good Group International Limited(2015) Yayınından Faydalanarak Hazırlanmıştır.

Tablo 1: 7 Sektöre Göre UMS'lerin Kapsamı 
Uluslararası Yönetim Íktisat ve İsletme Dergisi, ICAFR 16 Özel Sayısı Int. Journal of Management Economics and Business, ICAFR 16 Special Issue

\begin{tabular}{|l|l|l|l|}
\hline STANDART & $\begin{array}{l}\text { KAPSADIĞI } \\
\text { SEKTÖR } \\
\text { SAYISI }\end{array}$ & STANDART & $\begin{array}{l}\text { KAPSADIĞI } \\
\text { SEKTÖR } \\
\text { SAYISI }\end{array}$ \\
\hline UMS 1 & 7 & UMS24 & 7 \\
\hline UMS2 & 4 & UMS26 & 0 \\
\hline UMS7 & 7 & UMS27 & 0 \\
\hline UMS8 & 7 & UMS28 & 4 \\
\hline UMS10 & 7 & UMS29 & 0 \\
\hline UMS11 & 2 & UMS32 & 7 \\
\hline UMS12 & 7 & UMS33 & 7 \\
\hline UMS16 & 6 & UMS34 & 0 \\
\hline UMS17 & 6 & UMS36 & 5 \\
\hline UMS18 & 7 & UMS37 & 7 \\
\hline UMS19 & 5 & UMS38 & 6 \\
\hline UMS20 & 1 & UMS39 & 7 \\
\hline UMS21 & 7 & UMS40 & 2 \\
\hline UMS23 & 5 & UMS41 & 0 \\
\hline
\end{tabular}

Kaynak: E\&Y Good Group International Limited(2015) Yayınından Faydalanarak Hazırlanmıştır.

Çalışma kapsamında incelenen 7 sektörün tamamı toplam 12 UMS kapsamındadır. 5 standart çalışma kapsamındaki hiçbir sektörü ilgilendirmemektedir. Bu standartlar Tablo 1 de görüldüğü üzere UMS 26 Emeklilik Fayda Planlarında Muhasebeleştirme ve Raporlama, UMS 27 Bireysel Finansal Tablolar, UMS 29 Enflasyonlu Ekonomilerde Finansal Raporlama, UMS 34 Ara Dönem Finansal Raporlama, UMS 41 Tarımsal Faaliyetler standartlarıdır. UMS 26 standartı Türkiye'de OYAK ve çeşitli sandıklar olarak uygulanmaktadır. Dönemsel olarak şahıslardan toplanan fonlar belirli bir süre sonunda toplu olarak yada aylık maaş şeklinde şahıslara ödenmektedir. $\mathrm{Bu}$ son yıllarda Türkiye'de Bireysel Emeklilik Sistemini de kapsamaktadır. Ama BES bir sigorta değildir. Katılımcıları herhangi bir kazaya karşı sigortalamamaktadır. Bu yüzden bu standart sigorta sektörünü de kapsamamaktadır. UMS 27 Bireysel Finansal Tablolar standartı UFRS 10 ve UFRS 11 standartlarıyla birleştirildiği için uygulama kapsamında değildir. UMS 29 enflasyonist dönemlerde standartlarda yapılması gereken düzenlemeleri öngörmektedir. UMS 34 yalnızca ara dönem finansal tabloları kapsamaktadır. UMS 41 ise sadece tarımsal faaliyetlerde bulunan şirketleri kapsadığından çalışmaya konu olan 7 sektörü kapsamamaktadır (Karabınar, UMS'lerin kapsamı, 2016). 
Uluslararası Yönetim İktisat ve İșletme Dergisi, ICAFR 16 Özel Saylsı Int. Journal of Management Economics and Business, ICAFR 16 Special Issue

\section{Grafik 2:UFRS’lerin Sektörlere Göre Kapsamı}

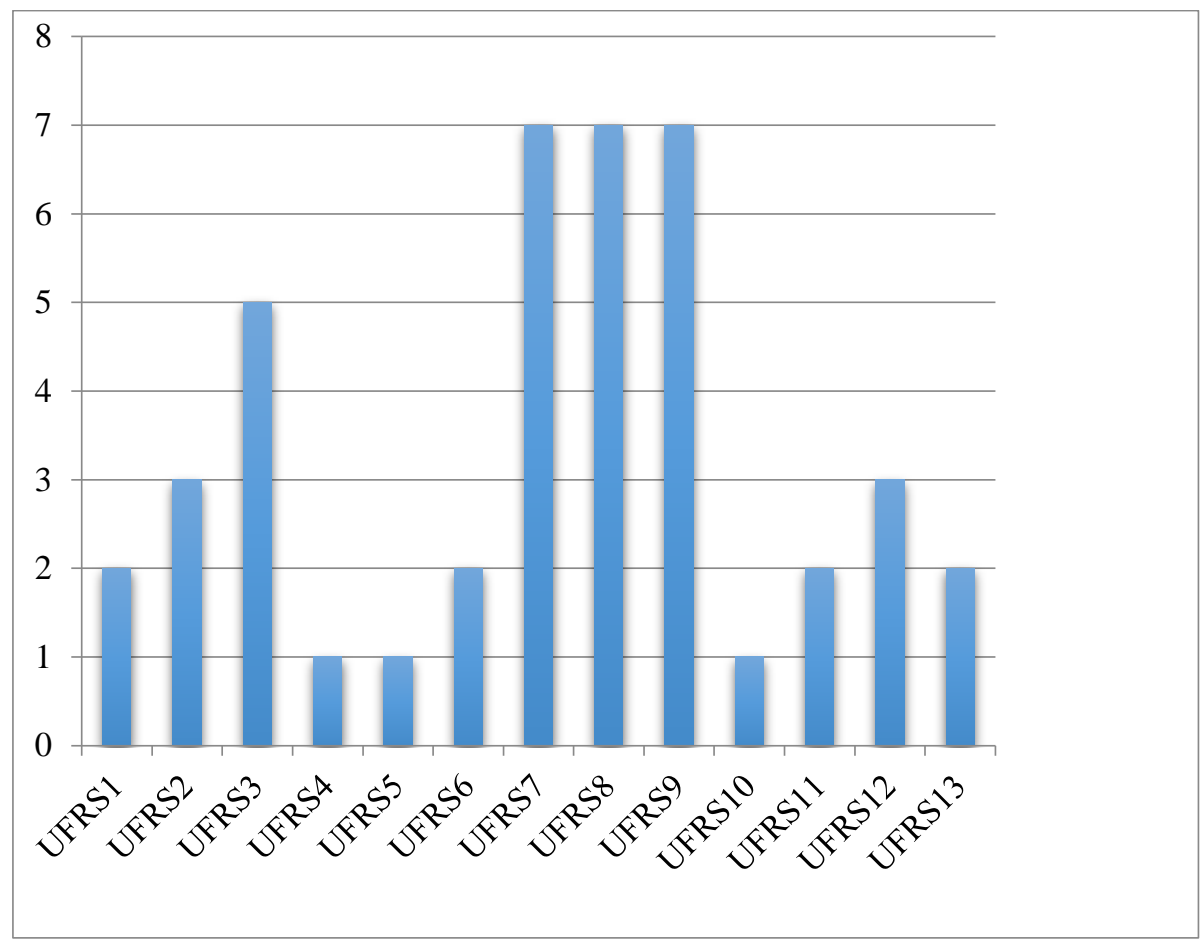

Kaynak: E\&Y Good Group International Limited(2015) Yayınından Faydalanarak Hazırlanmıştır.

Grafik 2'de UFRS'lerin 7 sektöre göre kapsamı gösterilmiştir. Grafiğge göre 3 standart (UFRS7, UFRS 8 ve UFRS 9) tüm sektörleri kapsamaktadır. 3 standart ise sadece 1 sektörü kapsamaktadır. UFRS 4: Sigorta Sözleşmeleri standartı yalnızca sigorta sektörünü kapsamaktadır. Çünkü bu standart sigorta sektörüne özgü hazırlanmıș ve sigorta ile reasürans şirketlerini ilgilendirmektedir. $\mathrm{Bu}$ yüzden diğer sektörleri kapsamamaktadır. UFRS 5 Satış Amaçlı Elde Bulunan Duran Varlıklar ve Durdurulan Faaliyetler Standartı 7 sektör arasında sadece gayrimenkul sektörünü ilgilendirmektedir, standart gayrimenkul şirketlerinin satma amacıyla almış oldukları gayrimenkullerin raporlanması ile ilgili açıklamalar yapmaktadır.

Ayrıca UFRS 10: Konsolide Finansal Tablolar Standartı da yalnızca gayrimenkul sektörünü kapsamaktadır. Çünkü konsolidasyonun temel kriteri konsolide yapılacak şirketlerin muhasebe politikaları ve finansal tablo formatlarının benzer nitelikte olması gerekmektedir. Diğer sektörlerin kendisine has finansal tablo formatlarına sahip olmaları konsolidasyonu mümkün kılmamaktadır. Gayrimenkul şirketlerinde de sermaye şirketlerinin yapısı konsolidasyona uymazken, şahıs şirketleri konsolidasyona uygun bir 
Uluslararası Yönetim Íktisat ve İsletme Dergisi, ICAFR 16 Özel Sayısı Int. Journal of Management Economics and Business, ICAFR 16 Special Issue

formata sahiptir (Karabınar, UFRS 10 Konsolide Finansal Tabloların Kapsamı, 2016). UFRS 7,8 ve 9 standartları tüm sektörleri kapsayan genel hükümlere sahip oldukları için çalışmadaki 7 sektörü de kapsamaktadır.

\section{Grafik 3: UFRS'lerin Sektörlere Göre Kapsamı}

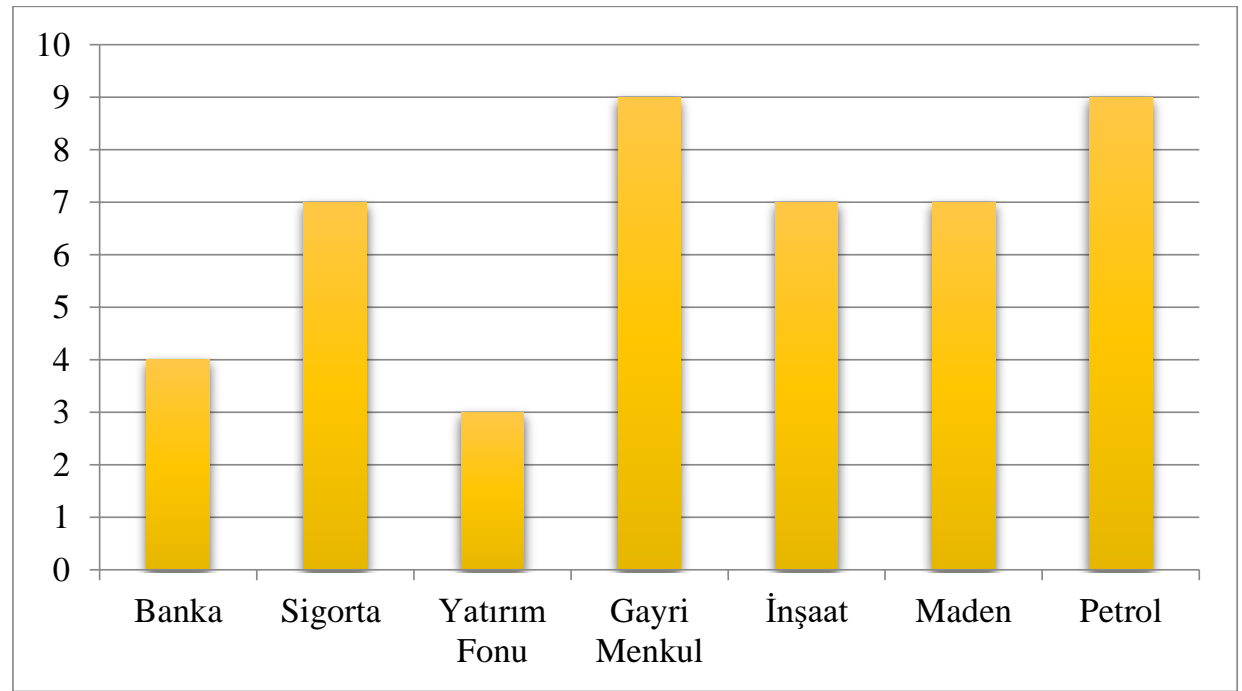

Kaynak: E\&Y Good Group International Limited(2015) Yayınından Faydalanarak Hazırlanmıştır.

Sektörler açısından UFRS'lerin kapsamının gösterildiği Grafik 3'e göre UFRS'ler en çok gayrimenkul (9 UFRS) ve petrol (9 UFRS) sektörlerini kapsamaktadır. Gayrimenkul sektörü UFRS 1, UFRS 4, UFRS 6 ve UFRS 13 standartları, Petrol sektörü ise UFRS 2, UFRS 4,UFRS 5 ve UFRS 10 standartları kapsam dişında tutulmuştur. UFRS'lerin kapsamının en az olduğu sektör 3 UFRS (UFRS 7, UFRS 8 ve UFRS 9) ile yatırım fonu sektörüdür.

Grafik 4:UMS Yorumlarının Sektörlere Göre Kapsamı

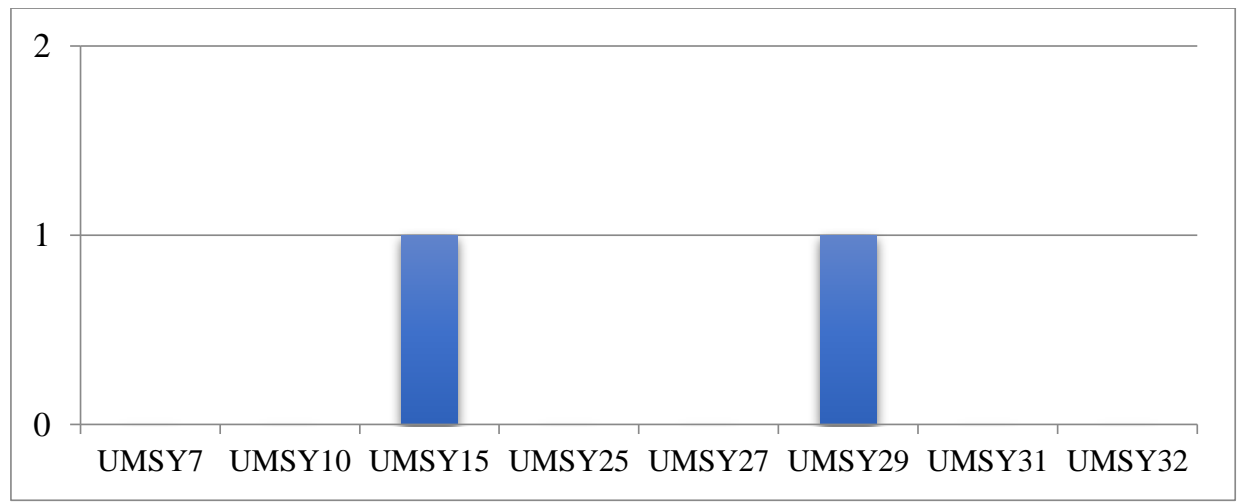


Uluslararası Yönetim Íktisat ve İsletme Dergisi, ICAFR 16 Özel Sayısı Int. Journal of Management Economics and Business, ICAFR 16 Special Issue

Kaynak: E\&Y Good Group International Limited(2015) Yayınından Faydalanarak Hazırlanmıștır.

Grafik 4 UMS yorumlarının 7 sektör açısından kapsamını göstermektedir. Grafiğe göre sadece 2 yorum belirlenen sektörleri kapsamına almaktadır. Bu yorumlar UMSY 15: Faaliyet kiralamaları- Teşvikler yorumu ve UMSY 29: İmtiyazlı Hizmet AnlaşmalarıAçıklamalarıdır.

Grafik 5:UMS Yorumlarının Sektörler Bazında Kapsamı

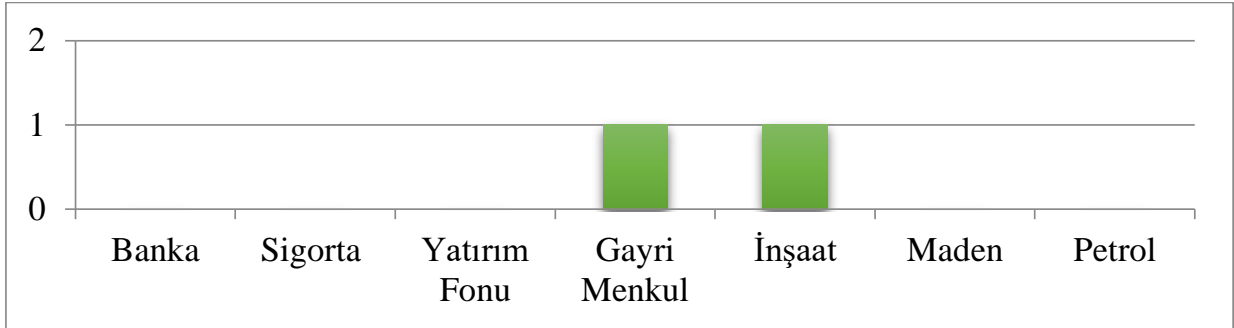

Kaynak: E\&Y Good Group International Limited(2015) Yayınından Faydalanarak Hazırlanmıștır.

Grafik 5 'te ise bu iki yorumun hangi sektörleri kapsadığını göstermektedir. UMSY 15 (Faaliyet Kiralamaları - Teşvikler) Gayrimenkul sektörünü, UMSY 29 (İmtiyazlı Hizmet Anlaşmaları - Açıklamalar) ise İnşaat sektörünü kapsamaktadır. UMSY 15'in konusu 09.03.2007 tarihli Resmi gazetede yayınlandığı üzere 'faaliyet kiralamasındaki teşviklerin kiracının ve kiraya verenin finansal tablolarına nasıl yansıtılması gerektiği' (kgk.gov.tr) olduğundan dolayı, üzerinde çalışılan sektörlere bakıldığında kiraya veren olarak sadece Gayrimenkul Sektörünü kapsayabileceği görülmektedir. Bu sebeple bu yorum çalışmada sadece Gayrimenkul sektörü için değerlendirilmeye alınmıştır.

Aynı tarihli Resmi gazetede yayınlanan UMSY 29' a bakıldığında konusunun 'imtiyaz tanınan ve imtiyaz tanıyan işletmelere ait finansal tabloların dipnotlarında kamuoyuna açıklaması gereken bilgilerin nelerden oluştuğu’ (kgk.gov.tr) bildirilmiştir. Aynı zamanda imtiyaz tanınan işletmeler ile hangi işletmelerin kastedildiği ve bu işletmeler arasında inşaat işletmelerin sayılabildiği bu kaynaktan elde edilebilecek veriler arasındadır. Bu sebeple UMSY 29'un çalışmanın kısıtları doğrultusunda sadece İnşaat sektörünü kapsadığı söylenebilir.

\section{Grafik 6:UFRS Yorumlarının Sektörlere Göre Kapsamı}

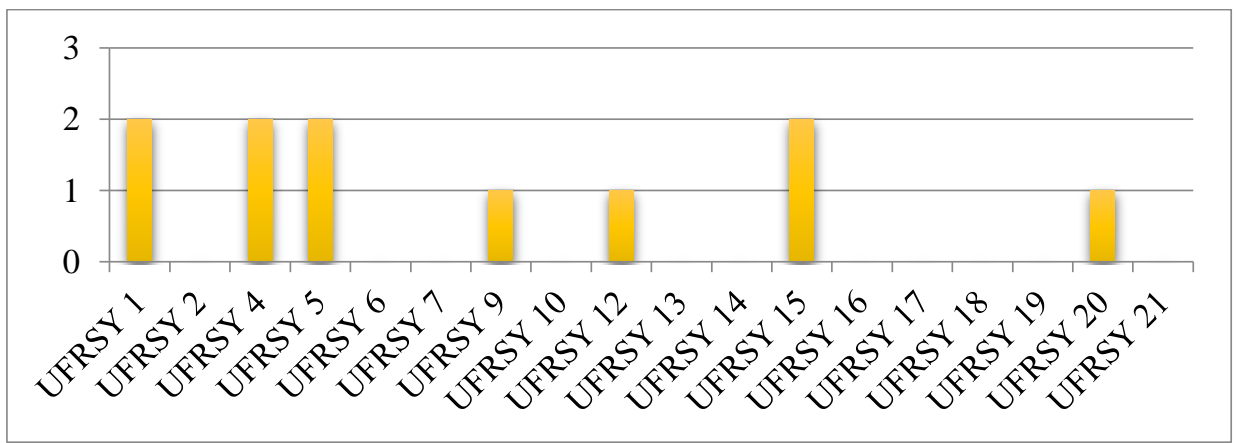

Kaynak: E\&Y Good Group International Limited(2015) Yayınından Faydalanarak Hazırlanmıştır. 
Uluslararası Yönetim İktisat ve İsletme Dergisi, ICAFR 16 Özel Sayısı Int. Journal of Management Economics and Business, ICAFR 16 Special Issue

Grafik 6 UFRS yorumlarının 7 sektör açısından kapsamını göstermektedir. Grafiğe göre 3 yorum 1, 4 yorum 2 sektörü kapsamak üzere 7 yorum belirlenen sektörleri ilgilendirmektedir. Sadece 1 sektörü kapsayan Yorumlar UFRSY 9 (Gömülü Türevlerin Yeniden Değerlemesi) , UFRSY 12 (İmtiyazlı Hizmet Anlaşmaları) ve UFRSY 20 (Açık İşletme Madeninin Üretim Aşamasındaki Dekapaj Maliyetleri)'dir. Aynı anda 2 Sektörü kapsamı altına alan yorumlar ise UFRSY 1 (Hizmetten Çekme, Restorasyon ve Benzeri Mevcut Yükümlülüklerdeki Değişiklikler), UFRSY 4 (Bir anlaşmanın kiralama işlemi içerip içermediğinin belirlenmesi), UFRSY 5 (Hizmetten Çekme, Restorasyon ve Çevre Rehabilitasyon Fonlarından Kaynaklanan Paylar Üzerindeki Haklar) ve UFRSY 15 (Gayrimenkul İnşaat Anlaşmaları)’tir. Ayrıca iki sektörü ilgilendiren ilk 3 yorumun her biri Maden ve Petrol sektörlerini, sonuncusunun ise Gayrimenkul ve İnşaat Sektörünü kapsadığını görülmektedir.

\section{Grafik 7:UFRS Yorumlarının Sektörler Bazında Kapsamı}

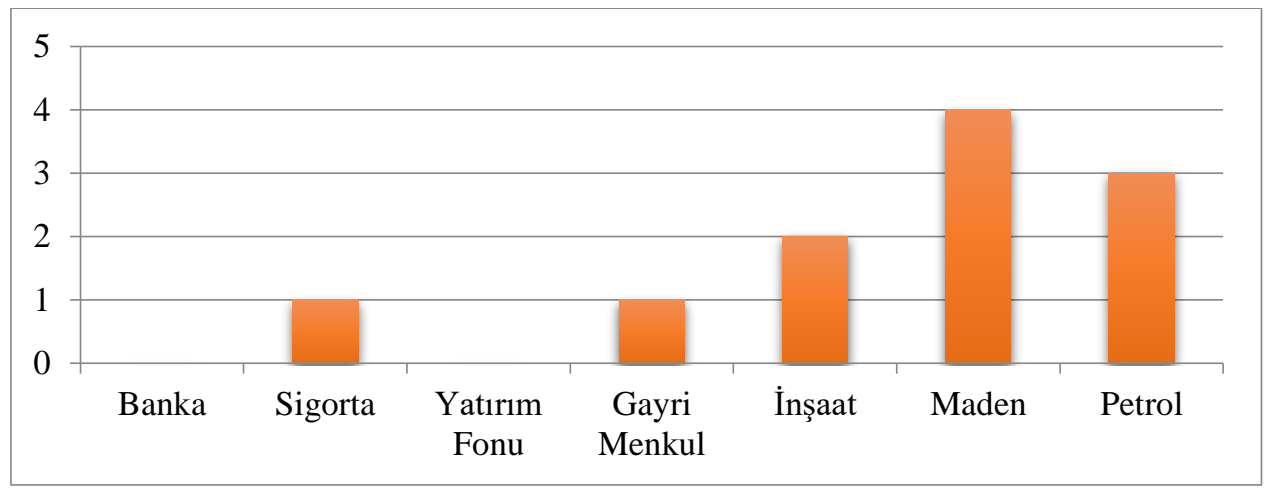

Kaynak: E\&Y Good Group International Limited(2015) Yayınından Faydalanarak Hazırlanmıştır.

Sektörler açısından UFRS Yorumlarının kapsama alanı incelendiğinde ise 4 yorum ile en çok Maden Sektörü'nü kapsamaktadır. Banka ve Yatırım Fonu Sektörünün ise herhangi bir yorumun kapsamı altına girmediği grafikten görülmektedir. Sigorta ve Gayrimenkul sektörlerinde birer yorum uygulama kapsamındadır. Sigorta sektöründe UFRSY 9 (Gömülü Türevlerin Yeniden Değerlemesi), Gayrimenkul sektöründe UFRSY 15 (Gayrimenkul İnşaat Anlaşmaları)'dir. UFRS 4 kapsamında hayat sigortaları içinde bulunan birikim unsuru ile risk unsurunun ayrıştırılması gerekmektedir. Birikim unsuru gömülü bir türev ürünüdür. $\mathrm{Bu}$ yüzden bu yorum sigorta sektörünü yakından ilgilendirmektedir. UFRSY 15 Gayrimenkul ve İnşaat sektörlerini kapsamına almaktadır. $\mathrm{Bu}$ yorum UMS 11 İnşaat Sözleşmeleri standartını yorumlayıcı mahiyette olduğundan UFRSY 15'de standartın uygulama kapsamı içinde olan bu iki sektörü kapsamaktadır.

\section{Sonuç Ve Değerlendirme}

7 sektörün incelendiği bu çalışmada UMS'ler, UFRS'ler ve yorumların çalışma kapsamındaki sektörler üzerindeki kapsamı analiz edilmiştir. Çalışmaya göre UMS'ler en çok İnşaat sektörünü kapsamaktayken, Yatırım Fonu sektörünü en az kapsamaktadır. Sektörel bazda UMS'lere bakıldığı zaman, 5 UMS'nin belirlenen sektörleri kapsamadığı görülmüştür. Sadece belirli sektörlerde kullanılan 3 tane standart mevcuttur (UMS 11: 
Uluslararası Yönetim İktisat ve İsletme Dergisi, ICAFR 16 Özel Sayısı Int. Journal of Management Economics and Business, ICAFR 16 Special Issue

İnşaat sözlelmeleri, UMS 20: Devlet Teşvikleri ve Muhasebeleştirilmesi, UMS40: Yatırım Amaçlı Gayrimenkuller).

UFRS'ler incelendiğinde 3 UFRS'nin tüm sektörlerde uıygulandığı, 3 UFRS'nin ise yalnızca birer sektörü kapsadığı belirlenmiştir. UFRS 4 Sigorta Şirketlerini, UFRS 5 ve UFRS 10 ise yalnızca Gayrimenkul sektörünü kapsadığı belirlenmiştir. UFRS ve UMS Yorumlarına bakıldığında UMS yorumlarından yalnızca UMSY 15 ve UMSY 29'un kapsam dahilinde olduğu belirlenmiştir. UMSY 15 Gayrimenkul sektörünü UMSY 29 ise İnşaat sektörünü ilgilendirmektedir. UFRS Yorumlarından ise 7 tanesinin ilgili sektörleri kapsadığ1 görülmüştür. Sektörel bazda bakıldığında yorumların en çok Maden sektörünü kapsadığ1 görülmüştür, en az ise Sigorta ve Gayrimenkul sektörünü kapsamaktadır.

Çalışmadan anlaşılacağı üzere Uluslararası Standartların büyük bir kısmı sektör gözetmeksizin tüm alanları kapsamaktayken, bazı standartlar ise belirli sektörlere özgü hazırlanmıştır.

\section{Kaynakça}

A.Quagli, \& F.Avallone. (2010). Fair Value or Cost Model? Drivers of Choice for IAS 40 in the Real Estate Industry. European Accounting Review, 19(3), 461-493.

Agostino, M., Drago, D., \& Silipo, D. B. (2011). The value relevance of IFRS in the European banking industry. Review of Quantitative Finance and Accounting (36), 437-457.

Akman, N. (2009). The Effect of IFRS Adoption on Financial Disclosure: Does Culture Still Play a Role. American International Journal of Contemporary Research, 1(1), 6-17.

Alfredson, K., Leo, K., Picker, R., Loftus, J., Clark, K., \& Wise, V. (2009). Appliying International Financial Reporting Standarts. Milton,Avustralya: Wiley\&Sons, Inc.

Кати Gözetim Китити. (b.t.). Ocak 24, 2016 tarihinde www.kgk.gov.tr: http://www.kgk.gov.tr/content_detail-345-1055-tms-tfrs-2015-seti.html adresinden alındı

Badem, A., \& Tosun, V. (2013). Yıllara Yaygın İnşaat İşlerinde Muhasebe Uygulamalarının Vergi Kanunları ve TMS 11 Açısından Karşılaştırılması ve Ertelenmiş Vergi Etkisi . Muhasebe ve Denetime Bakış, 103-124.

Başpınar, A. (2004). Türkiye'de ve Dünyada Muhasebe Standartlarının Oluşumuna Genel Bir Bakış. Maliye Dergisi, 42-57.

Bekçi, İ., \& Özdemir, O. (2006). Muhasebe Standartlarının Oluşum Süreci ve Türkiye Finansal Raporlama Standartlarına Yönelik Muhasebe Meslek Mensuplarının Bakış Açıları Üzerine Bir Araştırma. Süleyman Demirel Üniversitesi İktisadi ve İdari Bilimler Fakültesi Dergisi, 11(2), 143-164.

Bischof, J. (2009). The Effects of IFRS 7 Adoption on Bank Disclosure in Europe. Accounting in Europe, 6(2), 167-194. 
Uluslararası Yönetim İktisat ve Işsletme Dergisi, ICAFR 16 Özel Sayısı Int. Journal of Management Economics and Business, ICAFR 16 Special Issue

Bostanc1, S. (2002). Küreselleşen Muhasebede Standartlaşma ve Türkiye Muhasebe Standartları Kurulu. Mali Çözüm.

Brooks, M. (2008, Ocak). www.accountancymagazine.com. 01 19, 2016 tarihinde Accountancy Magazine. adresinden alındı

Christensen, H. B., \& Nikolaev, V. (2009). Who uses fair value accounting for nonfinancial assets after IFRS adoption. SSRN Working Paper, 01-46.

Cortese, C. (2013). Politicisation of the international accounting standard setting process: evidence from the extractive industries. Journal of New Business Ideas and Trends, 11(2), 48-57.

Çelik, T. Z., Gerekli, İ., Ertürk, S., Günay, Y., \& Bilginer, M. (2015). TMS 11 - İnşaat Sözleşmeleri. Kahramanmaraş Sütçü Imam Üniversitesi IIIBF Dergisi, 277-292.

DeFond, M., Hu, X., \& Li, S. (2011). The impact of mandatory IFRS adoption on foreign mutual fund ownership: The role of comparability. Journal of Accounting and Economics, 51(3), 240-258.

Epstein, B. J., \& K.Jermakowicz, E. (2010). Interpratation and Application of IFRS. Somerset,NJ: John Wiley \& Sons, Inc. .

Epstein, B. J., \& Mirza, A. A. (1999). Interpration and Application of International Accounting Standarts 2000. Somerset, New Jersey: John Wiley \& Sons, Inc.

Ernst\&Young. (2014). Good Group International Ltd. Illustratitive Financial Stataments. Euroville: Ernst\&Young.

Ernst\&Young. (2015). Good Group International Ltd. Illustrative Financel Statements. Eurovill: Ernst\&Young.

Firoz, M., Ansari, A., \& Akhtar, K. (2011). Industry, IFRS- Impact on Indian Banking. International Journal of Business and Management, 6(3), 277-283.

Gebhardt, G., \& Novotny-Farkas, Z. (2011). Mandatory IFRS Adoption and Accounting Quality of European Banks. Journal of Business Finance and Accounting, 38, 289333.

Gebhardt, G., Reichardt, R., \& Wittenbrink, C. (2004). Accounting for financial instruments in the banking industry. European Accounting Review, 13(2), 341371 .

Gutterman, S. (2013). The Coming Revolution in Insurance Accounting. North American Actuarial Journal, 6(1), 1-11.

Heykal, M., Sİagian, P., \& Iswandi. (2013). Impact Analysis Of Indonesian Financial Accounting Standard Based On The IFRS Implementation For Financial Instruments In The Indonesian Commercial Bank. 2nd World Conference on Business,Economics and Management (s. 1247-1250). Antalya: Procedia - Social and Behavioral Sciences.

IFRS. (2015, 7). 1 21, 2016 tarihinde International Financial Reporting Standarts: www.ifrs.org/ adresinden alınd 1 
Uluslararası Yönetim İktisat ve İsletme Dergisi, ICAFR 16 Özel Sayısı Int. Journal of Management Economics and Business, ICAFR 16 Special Issue

Karabınar, S. (2016, Şubat 4). UFRS 10 Konsolide Finansal Tabloların Kapsamı. (Ş. D. Demirci, Röportaj Yapan)

Karabınar, S. (2016, Şubat 5). UMS'lerin kapsamı. (Ş. D. Demirci, Röportaj Yapan)

Karaca, N., \& Misket, G. (2014). TMS 11 İnşaat Sözleşmeleri Standardı Kapsamında Muhasebe Uygulamaları. Gümüşhane Üniversitesi Sosyal Bilimler Elektronik Dergisi(10), 169-202.

Kikuya, M. (2001). International Harmonization of Japanese Accounting Standards. Accounting, Business \& Financial History, 349-368.

Kocamaz, H. (2012). Uluslararası Muhasebe Standartlarının Dünyada ve Türkiye'de Oluşum ve Gelişim Süreci. Kahramanmaraş Sütçü Imam Üniversitesi İktisadi ve Idari Bilimler Dergisi, 2(2), 105-120.

L.Cortese, C., Irvine, H. J., \& Koidonis, M. A. (2010). Powerful players: Howconstituents captured the setting of IFRS 6 , an accounting standard for the extractive industries. Accounting Forum, 76-88.

Manganaris, P., Spathis, C., \& Dasilas, A. (2015). The effects of mandatory IFRS adoption and conditional conservatism on European bank values. Journal of International Accounting,Auditing and Taxation(24), 72-81.

Muller, K. A., Riedl, E. J., \& Sellhorn, T. (2011). Mandatory Fair Value Accounting and Information Asymmetry: Evidence from the European Real Estate Industry. Management Science, 57(6), 1138-1153.

Nellessen, T., \& Zuelch, H. (2011). The reliability of investment property fair values under IFRS. Journal of Property Investment \& Finance, 29(1), 59-73.

Neveling, N. (2006, 02 16). www.accountancyage.com. 01 19, 2016 tarihinde Accountancy Age. adresinden alınd 1

Noel, C., Ayayi, A. G., \& Blum, V. (2010). The European Union's accounting policy analyzed from an ethical perspective: The case of petroleum resources, prospecting and evaluation. Critical Perspective on Accounting, 21(4), 329-341.

Oswald, B. (2008, 10 6). FASB and IASB Convergence: Implications for Investment Funds. 01 19, 2016 tarihinde Security Industry News: www.securityindustry.com adresinden alind 1

Özdemir, S. (2015). Bankalardaki Bölümsel Raporlama Uygulamalarının TFRS 8 Faaliyet Bölümleri Standardı Çerçevesinde İncelenmesi: Bir Uygulama Önerisi. Muhasebe ve Finansman Dergisi, 23-36.

Özkan, A., \& Aksoylu, S. (2012). Madencilik Endüstrisi: Muhasebe ve Finansal Raporlama. MÖDAV Dergi, 77-98.

Podoaba, L. (2015). An Empirical Research Regarding Density and Penetration Insurance on Accident \& Health Premiums in Future Implementation of Solvency II. Emerging Markets Queries in Finance and Business 2014, EMQFB 2014, (s. 1517-1524). Bükreş: Procedia Economics and Finance. 
Uluslararası Yönetim İktisat ve Işsletme Dergisi, ICAFR 16 Özel Sayısı Int. Journal of Management Economics and Business, ICAFR 16 Special Issue

Spies, F., \& Wilhelm, D. B. (2005). A critical analysis of US real estate appraisal methods when used for financial reporting according to the International Financial Reporting Standards ( IFRS ). 11th Annual Conference of the Pacific Rim Real Estate Society, (s. 1-17). Oestrich_Winkel/ Almanya.

Şenyiğit, Y. B. (2012). The Implementation of IFRS in the Turkish Insurance Industry. World Conference on Business, Economics and Management (BEM-2012) (s. 294300). Antalya: Procedia - Social and Behavioral Sciences.

Şişmanoğlu, E., \& Arıkboğa, D. (2011). Türkiye Finansal Raporlama SAtandartlarına (TFRS) Geçişin Sigorta Şirketleri Üzerindeki Etkileri. MÖDAV(4), 97-143.

Thappa, S. (2012). IFRSs in Indian Banking Industry-Challenges Ahead. International Journal of Finance and Accounting, 1(5), 94-105.

The International Financial Reporting Group of Ernst\&Young. (2010). International GAAP 2010. West Sussex, UK.: John Wiley \& Sons, Inc.

Türker, M., \& Yarbaşı, E. (2005). Globalization and Financial Reporting in Turkey. The Effects of Globalization on Financial Reporting (s. 50-90). İstanbul: İstanbul Commerce University Publication.

Uysal, C. (2001). Türkiye - Avrupa Birliği İlişkilerinin Tarihsel Süreci ve Son Gelişmeler. Akdeniz IIIBF Dergisi, 140-153.

Üstünel, B. (2003). Türkiye Muhasebe Standartları Kurulu ve Ulusal Finansal Raporlama Standartlar1. ismmmo.org.

Wiecek, I. M., \& Young, N. M. (2010). International GAAP Basics U.S. Edition. Hoboken, New Jersey: Wiley \& Sons Inc.

Yalkın, Y. K., Demir, V., \& Demir, L. D. (2008). International Financial Reporting Standarts (IFRS) and the Development of Financial Reporting Standarts in Turkey. Research in Accounting Regulation, 279-294.

Yereli, A. N., Kayalı, N., \& Demirlioğlu, L. (2011). İnşaat Sözleşmelerine İlişkin Türkiye Muhasebe Standartı (TMS 11) Çerçevesinde Yıllara Yaygın İnşaat Taahhüt İşlerinin Muhasebeleştirilmesi. Dokuz Eylül Üniversitesi Sosyal Bilimler Enstitüsü Dergisi, 113-135.

Yu, G., \& Wahid, A. S. (2014). Accounting Standarts and International Portfolio Holdings. The Accounting Review, 89(5), 1895-1930.

Yulong, P. (2005). Accounting for Insurance Contracts:Progress and Implications. Accounting Research.

Yücel, S., Öncü, M. A., \& Kartal, O. (2015). Türkiye'de Muhasebe Ve Finansal Raporlama Standartları Konularında Yayınlanmış Akademik Çalışmalar (20072014 Arası Literatür Taramas1). Muhasebe ve Finansman Dergisi, 39-66. 